\title{
Evlerde bulunan kullanım dışı ilaçlarla ilgili toplum farkındalığının araştırılması: bir pilot çalışma
}

\author{
Gürkan Köse1, Dilek Battal2, Ayça Aktaş2, Şahan Saygı
}

ÖZET: Evlerde bulunan kullanım dışı kalmış veya son kullanım tarihi geçmiş ilaçlar gün geçtikçe çevre ve insan sağlığı açısından büyüyen bir tehdit oluşturmaktadır. Bu çalışmada amaçlarımız (a) ailelerin evlerde kullanım dışı ve son kullanım tarihi geçmiş ilaçları bertaraf etme alışkanlıklarını belirlemek (b) bu ilaçların doğaya ve ekonomiye verebileceği potansiyel zararlara dikkat çekmek ve (c) bu konuda düzenlemelerle ilgili önerilerde bulunmaktır. Çalışmamızda, 18.11.2010-15.04.2011 tarihleri arasında Çukurova Bölgesinde yaşayan gönüllü 51 aileye anket uygulandı. Bu çalışmada ulaşılan 51 gönüllü ailenin \%82'sinin sosyal güvenceye sahip olduğu (SSK, Bağkur, Emekli Sandığı), geri kalan ailelerin (\%12) yeşil kart sahibi olduğu belirlenmiştir. Çalışmaya katılan ailelerin \%57'sinin çocuk sahibi olduğu; toplam çocukların \% 15,7'sinin 0 - 6 yaş grubunda olduğu saptanmıştır. Evlerde kullanım dışı kalmış ilaçların 288 kutu olduğu (6 kutu/aile) saptanmış olup bu ilaçların toplam maliyeti 4.666 TL (16.2 TL/ kutu) olarak saptanmıştır. Evlerde en fazla biriktiği belirlenen ilaç grupları sırasıyla analjezikler (\%20.1), solunum sistemi ilaçları (\%12.5) ve antibiyotiklerdir (\%9.7). Sonuç olarak, daha kapsamlı çalışmalar yapılarak oluşturulacak bilgi birikiminin sağlık çalışanları ile halka aktarılması ve sorunun çözümüne yönelik yasalar ve düzenlemeler yapılması gerekliliği göz ardı edilmemelidir.

ANAHTAR KELIMELER: Tıbbi atık; insan sağlığı; çevre; atık yönetimi; tıbbi atık yönetimi

\section{GiRiş}

İlaçlar doğru kullanıldığında, hastalıklara şifa olmasına rağmen kullanım süresi geçtiğinde veya kullanım dışı kaldığında vücudumuzda ne gibi etkilere yol açacağı öngörülemez bir durumdur. $\mathrm{Bu}$ etkiler, ilacın hangi koşullarda saklandığına, son kullanım süresinin ne kadar aşıldığına ve ne tür ilaçlarla aynı ortamda bulunduğu gibi pek çok etkene bağlıdır. İlaç kullanılmadan veya tamamen tüketilmeden kişinin sağlık durumunun düzelmesi, terapötik etkisi olmadığı için veya yan etkilerinden dolayı kullanımının hasta veya doktora bağlı olarak bırakılması, hastanın ilacı kullanmayı reddetmesi, ambalajın hastanın ihtiyacından fazla ilaç içermesi, tamamen tüketilmeden önce ilacın kullanım süresinin dolması gibi nedenlerle, tüketiciler ya da sağlık kurumlarında ilaç kullanılmayarak, atık durumuna dönüşebilir. İlaç üretiminin her yıl giderek büyük hacimlere ulaşması, beraberinde kullanım dışı kalmış ilaçların miktarını da artırmaktadir (1).

Hastaların ilaçların kullanımı hakkında yeterli bilgiye sahip olmamaları, hastanın tedavisinin yarım kalmasına sonrasında ise kullanılan ilaçların atık ilaç durumuna düşerek evlerdeki atık ilaç sayısının artmasına neden olmaktadır. Özellikle çocuklu ailelerde bulunan ilaçlar potansiyel zehirlenme riski taşır. Bu ailelerde miadını doldurmadığı halde riskli olan ilaçlar, atık ilaç olmasıyla daha da riskli hale gelmektedir. Amerika Birleşik Devletleri'nde ilaçların teminatsı depolama veya bertaraf edilmesinden dolayı en yaygın kaza ilaç zehirlenmeleridir. ABD'de, her yıl beş yaşın altında çok sayıda çocuk kasıtsız zehirlenme sonucu ölmektedir (2). Evlerde bulunan kullanım dişı
KURUM

1Eczacı, Adana,Türkiye.

2Mersin Üniversitesi,

Eczacılık Fakültesi

Farmasötik Toksikoloji

Anabilim Dalı, Mersin,

Türkiye

3Yakın Doğu Üniveristesi,

Eczacılık Fakültesi,

Farmasötik Toksikoloji

Anabilim Dalı, Lefkoşa, KKTC

ILETIŞIM

Dilek Battal

E-posta:

diakunal@yahoo.com

Gönderilme:

01.05.2013

Revizyon:

31.05.2013

Kabul:

31.05 .2013 
kalmış ilaç zehirlenmeleri ile ilgili araştırmalarda en çok ölümün çocukluk çağında olduğu belirtilmektedir (3-7).

Evlerde bulunan kullanım dışı kalmış ilaçların artması ve bilinçsizce bertaraf edilmesi çevre güvenliği açısından da tehlikelidir. Bazı ilaçlar, güvenlik ve etkinlik değerlerinin altında kullanılan dozu, bozulma ürünleri ve farklı biyolojik aktivite özelliklerinden dolayı insanlar, hayvanlar kısacası ekosistem üzerinde beklenmedik etkiler yapabilir $(8,9)$. 2002 yılında The U.S. Geological Survey (USGS), ilaçların ve diğer kişisel bakım ürünlerinin genellikle ülkenin yüzey sularında bulunduğunu ortaya koymuştur. USGS çalışmada, reçetesiz satılan ilaçların atıklarının akarsularda \% 80' den fazla olduğunu; reçetesiz antibiyotiklerin miktarının ise bu değerin yaklaşık yarısı kadar olduğunu tespit etmiştir (1). Yüzey sularında yüksek düzeyde antibiyotik bulunması, antibiyotiğe dayanıklı bakterilerin oluşmasına ve su bitkilerinde büyümenin azalmasına neden olmaktadır $(10,11)$.

Evlerde bulunan kullanım dışı kalmış ilaçların bir de ekonomik etki boyutu vardır. Atık ve kullanım dışı kalmış ilaçların miktarca artması ülkemiz ve dünya ekonomisini de etkilemektedir. Ülkemizde sağlık harcamalarının büyük çoğunluğunu ilaçlar oluşturmaktadır. Kamunun 1995 yılındaki ilaç harcaması 4.717 milyar TL iken; 2002 yılında bu rakam 12.72 milyar TL'ye yükselmiştir. 2010 yılında ise kamu ilaç harcaması 15.4 milyar TL'dir (12). Yine 2010 yılında kamu tarafından karşılanan ilaçlar 1.548 milyar kutudur. Bu verilerden de anlaşılacağ1 üzere ülkemizde ilaç harcamaları her geçen yıl büyümektedir. Kullanım dışı kalmış ilaçların veya sağlık ürünlerinin bulunması milyonlarca doların boşa gitmesi demektir (13-14). Araştırmacıların, sağlık hizmetleri endüstrisi tarafından üretilen ilaç atıkları ile ilgili çeşitli konuları ele almasına rağmen, ülkemizde ilaç atıklarının tam adresi ile ilgili literatürde yeterli çalışma bulunamamıştır. Çalışmamızda, ilaçların atık hale gelmesinin ardındaki sebepleri, atık ilaçların evlerde bulunma sıklığını, bu ilaçların farmakolojik sınıflandırılmalarını ve ayrıca anket çalışması uygulanan evlerde bulunan atık ilaçların ekonomik değerlerini inceledik. Amacımız atık ve artık ilaçlardan dolayı oluşabilecek potansiyel tehlikeler ile bunların doğaya ve ekonomiye verebileceği zararlar konusunda bilinç düzeyini pilot bir çalışma ile ortaya koymak, atık ve artık ilaç oluşumunu azaltmak ile ilgili önerilerde bulunmaktı.

\section{GEREÇ VE YÖNTEM}

Çalışmanın yapıldığı Çukurova Bölgesi, nüfus (yaklaşık 3.5 milyon) ve toprak ( $3150 \mathrm{~km}^{2}$ ) yoğunluğu bakımından Akdeniz Bölgesinin önemli bir kısmını oluşturmaktadır. Pilot çalışma yapılmak üzere, tanımlayıcı nitelikte ölçek kullanılmadan hazırlanan anket formu, 18.11.2010-15.04.2011 tarihleri arasında Çukurova Bölgesinde (Mersin, Adana ve Hatay illerinde), yakın çevremizde yaşayan, rastgele seçilen ve çalışmaya katılmayı kabul eden 51 aileye, ev ziyaretleri yapilarak ve aileler ile yüz yüze görüşülerek uyguland1. Anket formu uygulanan kişiler çalışma ile ilgili bilgilendirilerek, cevapları ile ilgili herhangi bir yönlendirmede veya zorlamada bulunulmad. Hazırlanan anket formunun birinci bölümünde çalışmanın içeriğini belirleyen açıklama, ikinci bölümünde katılımcıların demografik bilgilerini belirlemeye yönelik sorular, üçüncü bölümde ise evlerde ilaçların nerelerde saklandığını, kullanım dışı kalmış ilaçların hangi grup ilaçlar olduğu ve neden kullanım dışı kaldığını, kullanım dışı kalan ilaçların nasıl bertaraf edildiğini belirlemeye yönelik sorular yer almaktaydı.

\section{BULGULAR VE TARTIŞMA}

Ankete katılan 51 ailenin toplam birey sayıs 158'dir. Katılımcıların \%32.28'i 0-18 yaş aralığında çocuk, \%37.34' ü 2065 yaş aralığında yetişkin erkek, \%30.38'i 21-69 yaş aralığında yetişkin kadındır (Şekil 1). Anket sonuçlarına göre ailelerin \% 57 'sinin çocuk sahibi olduğu bunlardan bir çocuk sahibi olan 13, iki çocuk sahibi olan 10 ve üç çocuk sahibi olan 6 aile olduğu tespit edildi (Tablo 1). Anket uygulamasına katılan ailelerin büyük çoğunluğunun (\%82) sosyal güvencelerinin, sosyal güvenlik kurumuna ait Emekli Sandığı, SSK ve Bağ-Kur olduğu ve geri kalan ailelerin (\% 18) ise Yeşil Kart sahibi olduğu saptanıldı (Şekil 2).

TABLO 1. Ankete katılan ailelerdeki çocuk sayısı

\begin{tabular}{ccccccc}
\hline & \multicolumn{6}{c}{ Yaş Aralığı (Yı) } \\
\cline { 2 - 7 } Çocuk Sayısı & $0-1$ & $1-3$ & $3-6$ & $6-12$ & $12-15$ & $15-18$ \\
& -- & 2 & 6 & 14 & 13 & 16
\end{tabular}

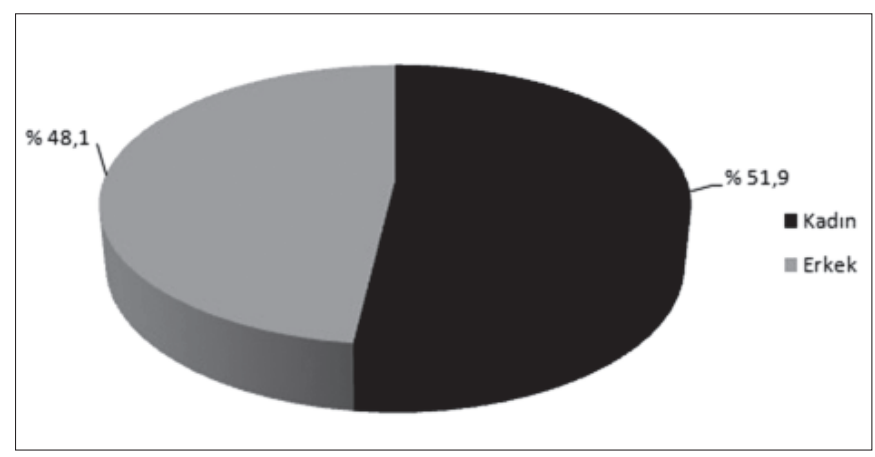

ŞEKiL 1. Çalışmaya katılanların cinsiyetlerine göre dağılımı.

Ailelerin beyanlarına göre evlerde kullanım dışı kalmış ilaçların 288 kutu olduğu, başka bir ifade ile aile başına yaklaşı 6 kutu ilaç düştüğü saptandı. Bu ilaçlar farmakolojik etkilerine göre sınıflandırıldığında ise en fazla ilacın Analjezik (NSAİ) olduğu görüldü (Şekil 3). Evlerde kullanım dışı kalan toplam 288 kutu ilacın fiyatı piyasa satış bedelleri göz önüne alınarak, $4.666 \mathrm{TL}$, ortalama kutu fiyatı ise 16.2 TL olarak saptanmıştır. Anket sonuçlarına göre evde bulunan kullanım dışı kalmış ilaçların, aile başına ortalama 91.5 TL’lik dağılım gösterdiği gözlenmiştir.

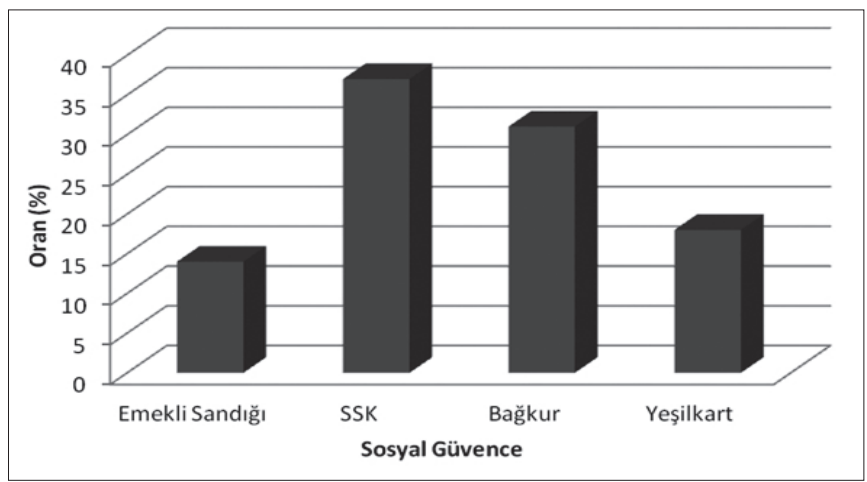

SSK: Sosyal Sigortalar Kurumu

ŞEKiL 2. Ankete katılan ailelerin sosyal güvenceleri. 


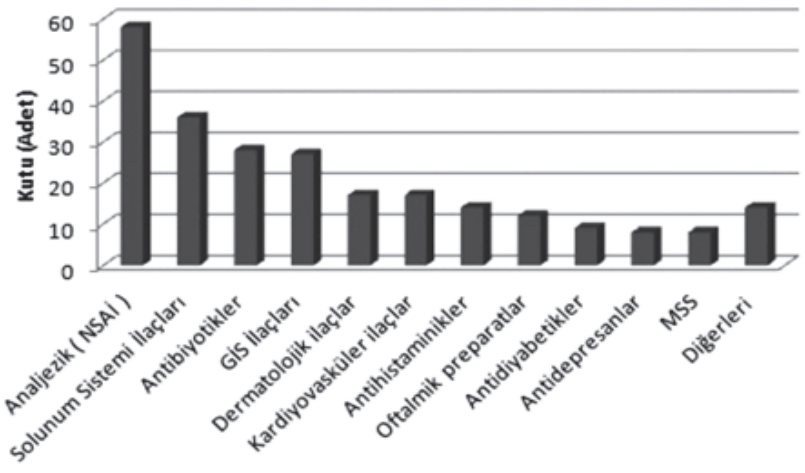

GiS: Gastrointestinal Sistem İlaçları MSS: Merkezi Sinir Sistemi İlaçları

ŞEKiL 3. Evlerde bulunan kullanım dışı kalmış ilaçların farmakolojik gruplandırılması.

Çalışmamızda yer alan ailelerde, ilaçların en fazla hangi nedenlerle kullanım dışı kaldığı araştırılmış ve sıklıkla kullanım süresinin dolması, hastaların tedavi sürecini yarıda kesmesi, doktorun aynı etki mekanizmasına sahip başka bir ilacı önermesi sebeplerinden dolayı ilaçların kullanım dışı haline geldiği belirlenmiştir. Bu ilaçları farmakolojik olarak sınıflandırdığımızda reçetesiz ve kolay ulaşılabilir olmaları ile ilgili olarak ilk sırayı \% 20.1 oranında analjezik ilaçlar almaktadır (Şekil 3). İkinci sırada astım hastalarının bölgedeki yoğunluğu nedeni ile solunum sistemi ilaçları yer almaktadır (15). Bizim çalışmamızda üçüncü sırada yer alan antibiyotiklere, literatürdeki çalışmalarda sık rastlanmaması önemli bir noktadır (16). Bunun en önemli sebebi Avrupa Birliği ülkelerinde yürürlükte olan ilaç uygulamalarına göre hastalara tedavisini bitirecek sayıda antibiyotik verilmesi ve devletin bu sınırın üstündeki antibiyotik alımları için herhangi bir ödeme yapmamasıdır $(17,18)$. Ülkemizde gastrointestinal sistem (GİS) ilaçlarının hastalar tarafından yoğun bir şekilde kullanımına bağlı olarak bu grupta yer alan ilaçlar \% 9.4 oranla antibiyotikleri takip ederek dördüncü sırada yer almaktadır (19-22). Genel olarak topikal kortikosteroidlerin yer aldığı, krem, merhem veya jel preparatları halinde bulunan dermatolojik ilaçlar çalışmamızda GİS ilaçlarından sonra gelen ilaç grubudur (Şekil 3). Schwab ve ark. yaptığı çalışmada yüzey sularında belirlenen ve mataboliti aktif olan ilaçlar sıralamasında kardiyovasküler ilaçlar üst sıralarda yer almaktadır (23). Çalışmamızda da birden fazla ilaç kullanan hasta sahibi ailelerde kullanım süresi geçmiş kardiyovasküler ilaçlara sıklıkla rastlanmıştır. Antihistaminik ilaçlar neredeyse her evde rastladığ1mız bir ilaç grubudur. Bu gruptaki ilaçları hastalar alerjik rahatsızlıkların yanı sıra uyku verici, sedatif etkilerinden dolayı da kullanmaktadırlar. Ailelerin evlerde ilaç saklama yerleri genellikle, buzdolabı, mutfak veya banyo dolaplarının içi olarak belirlenmiştir. Ailelerin ilaçları bertaraf etme yöntemleri arasında ise en çok tercih edilenin çöpe, lavaboya veya tuvalete dökme yöntemi olduğu gözlenmiştir.
Anket uygulanan 51 evde toplam 288 adet atık ilaç belirlenmiştir. Belirlenen atık ilaçların toplam maliyeti ise 4666 Türk Lirası olarak belirlenmiştir. Aile başına belirlenen atık ilaç maliyeti ise 91,5 TL'dır. Çalışmaya katılan ailelerin \% 82' sinin sosyal güvencesi olduğu geri kalan \% 18' inin ise ilaç harcamalarını yeşil kart ile karşıladı̆̆ı belirlenmiştir (Şekil 2). Bu veriler, belirlenen atık ilaçlara ait maliyetin tamamının devlet tarafından karşılanan ilaç harcaması olduğunu göstermektedir. İspanya' da 2007 yılında yapılan bir çalışmada, 227 hasta, 8 gün içerisinde evlerinde kullanmadıkları 1176 paket ilacı geri getirmişlerdir. İlaçların toplam mali değeri 8.540 Euro olarak bildirilmiştir. Bu miktarın 6.464 Euro'luk bedeli devlet tarafından karşılanan ilaç harcaması olarak belirlenmiştir (11). Yapılan çalışmalara mali açıdan bakılacak olursa atık ve kullanım dışı kalmış ilaçların devletlerin ve kişilerin bütçesine ağır yükler getirdiği açıkça görülmektedir (24-28).

Evlerde bulunan kullanım dişı ilaçların, insan ve çevre sağlığına yönelik potansiyel tehlikelerinin azaltılması amacı ile alınacak önlemler şöyle sıralanabilir:

- İlaç firmaları daha az miktarda ilaç içeren ambalajlar piyasaya sürmelidir.

- Atık ilaçların insan, ekosistem ve ekonomik açıdan potansiyel tehlikelerinin anlatıldı̆̆ı eğitimler ve çalıştaylar düzenlenerek toplumun konu ile ilgili farkındalık düzeyi artırılmalıdır.

- Kullanılmayan veya atılan ilaçların türleri ve miktarları oluşturulacak takip sistemi ile belirlenmeli ve daha bilinçli reçete uygulamaları yapılmalıdır.

- Atık ilaçların evlerden toplanması ve tıbbi atık arıtma tesislerine ulaştırılması sistematik yapılarak var olan atık ilaçların ekolojik sisteme zarar vermeden yok edilmesi sağlanmalıdir (29-33).

Çalışmamızın, anket oluşturma ve uygulama, toplumu yansıtma basamaklarında (olgu sayısının az olması ve sınırlı bir bölgede uygulanmış bir çalışma olması) kısıtlı yönler vardır. Ancak elde ettiğimiz sonuçlar değerlendirildiğinde, çalışmanın daha geniş bir seri ile ve çok merkezli yapılacak çalışmalara ön bilgi sağlayacağı ve konuya dikkat çekeceği gözlenmektedir.

Sonuç olarak, yapılan pilot çalışma ile Ülkemizde de atık ve artık ilaçların çevreye, insanlara ve ekonomiye verdiği zararlar konusunda, gelişmiş ülkelerde olduğu gibi, geniş kapsamlı projelere, toplumun her kesimi için farkındalık düzeyini artırıc1 eğitim çalışmalarına ve yasal düzenlemelere gereksinim olduğu gözlenmiştir. Daha kapsamlı çalışmalar yapılarak oluşturulacak bilgi birikiminin sağlık çalışanları ve halka aktarılmasıyla sorunun çözümüne yönelik yasal düzenlemeler yapılması gerekliliği göz ardı edilmemelidir. 


\section{Assessing of public awareness concerning unused medicines in households: a pilot study}

ABSTRACT: Unused and expired medicines kept in households pose a growing threat to the environment and human health day by day. Our purposes in the present study are (a) to determine families' habits of dispose for unused and expired medicines accumulating in households., (b) to get noticed on potentially detrimental effects to the nature and the economy of this medicines and (c) to give some suggestions on harmonization for this medicines. Within the scope of the study, questionnaires were applied to $\mathbf{5 1}$ voluntarily participating families living in Cukurova Region between 18.11.2010 and 15.04.2011. In the study it was determined that $82 \%$ of the total 51 participating families were covered by social security (either through Social Security Authority, Bagkur as the Turkish social security organization for artisans and the self-employed or retirement fund), $12 \%$ of the remaining families had green card, $57 \%$ of the families were with children and $15.7 \%$ of these children were within the age group of $0-6$. It was determined that there were a total of 288 packages of unused and expired medicine (6 packages/family). While the medicine groups which were determined to be accumulated the most in households were analgesics $(20.1 \%)$, respiratory system related medicines $(12.5 \%)$ and antibiotics $(9.7 \%)$. In conclusion, the necessity to carry out further and more comprehensive studies for transferring the obtained information to health professionals and to the public, and to enact laws and regulations intended for the solution of the problem has to be taken into consideration.

KEYWORDS: Pharmaceutical waste, human health, environment, waste management, pharmaceutical waste management

\section{KAYNAKLAR}

1. Boxall, Alistair B. The environmental side effects of medication. European Molecular Biology Organization Reports 2004; 5: 1110-6.

2. United States Consumer Product Safety Commission. 2005 Annual report of all-terrain vecihle (ATV)-related death and injuries. PDF Dokümanı. [http://www.cpsc. gov/PageFiles/87678/atv2005.pdf; Erişim Tarihi: 26 Ağustos 2013].

3. National Suicide Prevention Strategy for England. PDF Dokümanı [http://www.nmhdu.org.uk/silo/files/ national-suicide-prevention-strategy-for-england.pdf; Erişim Tarihi: 26 Ağustos 2013].

4. De Bolle L, Mehuys E, Adriaens E, Remon JP, Van Bortel L, Christiaens T. Home medication cabinets and selfmedication: a source of potential health threats? Ann Pharmacother 2008; 42: 572-9.

5. Ruhoy IS, Daughton CG. Beyond the medicine cabinet: An analysis of where and why medications accumulate. Environ Int 2008; 34: 1157-69.

6. Herring ME, Shah SK, Shah SK, Gupta AK. Current Regulations and Modest Proposals Regarding Disposal of Unused Opioids and Other Controlled Substances. J Am Osteopath Assoc 2008; 108: 338-43.

7. İlkkurşunlu Ş. İlaç atık ve bertaraf projesi. [www.atikilac. com/Evsel_Atik.pps.; Erişim Tarihi: 26 Ağustos 2013].

8. Şahan S, Battal D, Şahin NÖ. Çevre ve insan sağlığ1 yönünden ilaç atıklarının önemi. Marmara Pharm J 2012; 16: 82-90.

9. Bound JP, Voulvoulis N. Household disposal of pharmaceuticals as a pathway for aquatic contamination in the United Kingdom. Environ Health Perspect 2005; 113: 1705-11.

10. Daughton CG, Ternes TA. Pharmaceuticals and personal care products in the environment: Agents of subtle change? Environ Health Perspect 1999; 107: 907-38.

11. Coma $A$, Modamio $P$, Lastra CF, Bouvy ML, Mariño EL. Returned medicines in community pharmacies of Barcelona. Pharm World Sci 2008; 30: 272-7.
12. Akdağ R. SAĞLIK BAKANLIĞI 2011 Mali Yılı Bütçesinin T.B.M.M. Genel Kurulu'na Sunumu. 22 Ekim 2012. http:/ / www.saglik.gov.tr/BAKAN/dosya/1-70836/h/ saglik-bakanligi-2011-butce.

13. Polat $A$,Varınca $K B$. Beşeri ilaç üretiminde tehlikeli atık yönetimi. 28 Ekim 2010. http://www.yildiz.edu. $\mathrm{tr} / \sim \mathrm{kvarinca} /$ Dosyalar/Yayinlar/yayin016.pdf.

14. Akar $T$, Derinöz $O$, Demirel B. İlaç zehirlenmeleri ve hastane maliyetleri. Turk Arch Ped 2007; 42: 103-6.

15. Bayram I, Güneşer-Kendirli S, Yilmaz M, Altintaş DU, Alparslan N, Bingöl-Karakoç G. The prevalence of asthma and allergic diseases in children of school age in Adana in southern Turkey. Turk J Pediatr 2004; 46: 221-5.

16. Bilgili N, Karatay G. Sait Yazıcı Sağlık Ocağı Bölgesinde Yaşayan Bireylerin İlaç Tüketimi İle İlgili Bazı Uygulamalarının Belirlenmesi. Hemşirelik Yüksekokulu Dergisi 2005; 39-48.

17. Proper disposal of expired or unwanted drugs. Pharmacist's Letter / Prescriber's Letter 2007; 23: Detail-Document \#230401. [Erişim Tarihi: 26 Ağustos 2013].

18. Witte W. Medical Consequences of Antibiotic Use in Agriculture. Science 1998; 279: 996-7.

19. Akar $T$, Derinöz $O$, Demirel B. İlaç zehirlenmeleri ve hastane maliyetleri. Turk Arch Ped 2007; 42:103-6.

20. T.C. SAĞLIK BAKANLIĞI. 2011 Mali Yılı Bütçesinin T.B.M.M. Plan ve Bütçe Komisyonu'na Sunumu. 23 Kasim 2010. http://www.saglik.gov.tr/TR/dosya/170239/h/2011-butce.pdf

21. Deniz V. Evimizdeki Tehlikeli Atıklar. Geri Dönüşüm Dergisi 2008; 12-14.

22. Kuemmerer $K$. Antibiotics in the aquatic environment $A$ review part II. Chemosphere 2009; 75: 435-41.

23. Schwab BW, Hayes EP, Fiori JM, Mastrocco FJ, Roden NM, Cragin D, Meyerhoff RD, D'Aco VJ, Anderson PD. Human pharmaceuticals in US surface waters: a human health risk assessment. Regul Toxicol Pharmacol 2005; 42: 296-312. 
24. Zuccato E, Castiglioni $S$, Bagnati R, Melis M, Fanelli R. Source, occurrence and fate of antibiotics in the Italian aquatic environment. J Hazard Mater 2010; 179: 1042-8.

25. Ekedahl AB. Reasons why medicines are returned to Swedish pharmacies unused. Pharm World Sci 2006; 28: 352-8.

26. Makris KC, Snyder SA. Screening of pharmaceuticals and endocrine disrupting compounds in water supplies of Cyprus. Water Sci Technol 2010; 62: 2720-8.

27. Langdon KA, Warne MS, Smernik RJ, Shareef A, Kookana RS. Selected personal care products and endocrine disruptors in biosolids: an Australia-wide survey. Sci Total Environ 2011; 409: 1075-81.

28. Hemminger P. Damming the flow of drugs into drinking water. Environ Health Perspec 2005; 113: A678-81.

29. Potera C. Drugged drinking water. Environ Health Perspect 2000; 108: A446.
30. Fent K, Weston AA, Caminada D. Ecotoxicology of human pharmaceuticals. Aquat Toxicol 2006; 76: 122-59.

31. Natural Resources Defense Council White Paper: Dosed without prescription preventing pharmaceutical contamination of our nation's drinking water. [http:/ / docs. nrdc.org/health, Erişim Tarihi: 26 Ağustos 2013].

32. TDC Environmental, Household Pharmaceutical Waste: Regulatory and Management Issues. San Francisco, 2004. PDF Dokümanı [http://www.tdcenvironmental.com/ HouseholdPharmWasteMgtIssuesFinal.pdf Erişim Tarihi : 26 Ağustos 2013].

33. U.S. EPA Great Lakes National Program Office, Disposal of Unwanted Medicines: A Resource for Action in Your Community. PDF Dokümanı [http://www.seagrant.sunysb. edu/Images/Uploads/PDFs/RUMDoseofReality-UnwantedMedsToolkit.pdf; Erişim Tarihi: 26 Ağustos 2013]. 